\title{
20 ANOS DO PROGRAMA DE PÓS-GRADUAÇÃO EM TURISMO E HOTELARIA
}

Doris van de Mene Ruschmann ${ }^{1}$

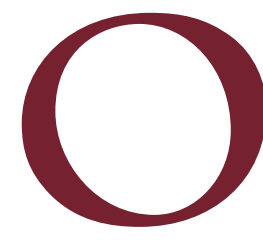
programa de Pós-Graduação Stricto Sensu em Turismo e Hotelaria teve o seu início no ano de 1997, sendo o primeiro Programa de Mestrado em Turismo do sul do Brasil. A área de atuação é o Planejamento e Gestão do Turismo e Hotelaria e possui duas linhas de pesquisas: Planejamento do Destino Turístico (LPI) e Gestão das Empresas de Turismo (LPII).

O PPGTH mantém a sua visão, missão e objetivos até os dias de hoje. A Visão de ser um Programa de Pós-Graduação Stricto Sensu, reconhecido na comunidade científica pela excelência em formar pesquisadores e docentes em Turismo e Hotelaria, em consonância com as necessidades da sociedade como um todo.

A Missão de constituir-se como um centro de excelência em Mestrado e Doutorado em Turismo e Hotelaria que desenvolve competências para a educação e pesquisa, produz e difunde conhecimento, promove a reflexão crítica visando o desenvolvimento social-ambiental-econômico-cultural por meio de pesquisas envolvendo docentes e discentes com instrumental e recursos adequados.

Como objetivos: Incentivar a pesquisa e o aprofundamento de estudos relacionados ao campo do turismo; Estimular o embasamento científico dos estudos e pesquisas do turismo no país; Criar um corpo de pesquisadores e de docentes de alto nível, capaz de analisar e avaliar todos os aspectos da atividade turística tanto no país como no exterior; Produzir e disseminar conhecimento técnico-científico na área do turismo e hotelaria; Promover a titulação acadêmica em nível de mestrado e doutorado dos profissionais e docentes da área de turismo e hotelaria; Capacitar recursos humanos para o ensino do turismo nos 1 Prof. ${ }^{a}$ Dra. Doris van de Mene Ruschmann: Coordenadora do Programa de Pós-Graduação Stricto Sensu em Turismo e Hotelaria - PPGTH de 1997 a 2012. 
níveis técnico, de graduação e de pós-graduação; Melhorar a qualidade do ensino do turismo no país.

O corpo docente no seu ano de criação era composto pelos seguintes professores: Dr. Alejandro Adolfo Torchiaro; Dra. Antonia Marisa Canton; Dra. Doris van de Meene Ruschmann (coordenadora); Dr. Gino Giacomini Filho; Dr. Guilherme Guimarães Santana; Dr. Hugo Osvaldo Acosta Reinaldo; Dra. Josildete Pereira de Oliveira, Dr. Marcus Polette; Dr. Mário Carlos Beni; Dr. Osmar de Souza; e Dr. Paulo dos Santos Pires. A primeira turma de Mestrado do Programa de Pós-Graduação em Turismo e Hotelaria teve 24 alunos inscritos, mostrando a importância e a necessidade da criação de um programa Stricto Sensu nesta área do conhecimento no Brasil.

No ano de 1998, com o objetivo de comunicar o conhecimento científico, é criada a Revista Turismo - Visão e Ação (RTVA). O periódico, em suas primeiras edições, foi publicado na íntegra no formato bilíngue, mostrando o compromisso do PPGTH com a internacionalização. A RTVA teve como sua primeira editora a professora Dra. Doris Van de Meene Ruschmann e os editores atuais são os professores Dr. Luciano Torres Tricárico e Dr. Luiz Carlos da Silva Flores. A RTVA atualmente goza do conceito Qualis/CAPES B1 e está em processo de avaliação no Scielo e no Redalyc, em consonância com o compromisso do PPGTH com o rigor científico e com a internacionalização.

A primeira avaliação pela qual o Programa de Pós-Graduação em Turismo e Hotelaria foi submetido pela CAPES foi no ano de 1999 e o seu primeiro conceito foi o conceito 3. No ano seguinte, outra data importante na história do PPGTH foi a primeira defesa de dissertação, que ocorreu no dia 22 de agosto, intitulada "Cabeçudas 1910 - 1930: A praia como padrão de conduta social". A defesa foi do aluno Angelo Ricardo Christoffoli sob orientação da Dra. Roselys Izabel Correa dos Santos e teve como membros da banca os seguintes avaliadores: Dr. João Klug e Dra. Raquel Maria Fontes do Amaral Pereira.

Nas dependências do PPGTH, no dia 08 de novembro de 2002, a Associação Nacional de Pós-Graduação em Turismo (ANPTUR) foi fundada. O Programa de Pós-Graduação em Turismo e Hotelaria esteve presente e atuante numa das reuniões de maior relevância para a área. Na data em questão, pesquisadores 
das seguintes universidades estiveram presentes: Universidade do Vale do Itajaí, Universidade de Caxias do Sul, Universidade Anhembi Morumbi, Universidade Estadual de Santa Cruz e Universidade de São Paulo.

A avalição da CAPES, que atribuiu o conceito 4 ao Programa, ocorreu em 2007 (referente ao período de 2004 a 2006), quando da iniciativa de integrar os mestrados de Turismo e Hotelaria e Administração, o que proporcionou a oportunidade de se criar o Programa de Doutorado em Administração e Turismo. No ano de 2010, o PPGTH foi novamente reavaliado pela CAPES e nesta avaliação teve uma alteração do conceito, passando do conceito 4 para o conceito 5 (conceito que se mantém até os dias atuais). O Programa de PósGraduação em Turismo e Hotelaria na época foi o único Programa de Turismo agraciado com o conceito máximo da CAPES, refletindo a pesquisa de qualidade no campo do Turismo e Hotelaria.

Mantendo o espírito de vanguarda do PPGTH, no ano de 2013 o doutorado Stricto Sensu em Turismo e Hotelaria teve o seu início, sendo o primeiro Programa de Doutorado em Turismo e Hotelaria do Brasil. O corpo docente no seu ano de criação era composto pelos seguintes professores: Dr. Carlos Alberto Tomelin; Dra. Doris van de Meene Ruschmann; Dra. Fabrícia Durieux Zucco; Dr. Francisco Antonio dos Anjos (coordenador); Dra. Josildete Pereira de Oliveira; Dr. Luciano Torres Tricárico; Dr. Luiz Carlos da Silva Flores; Dr. Paulo dos Santos Pires; Dra. Rafaela Vieira; Dra. Raquel Maria Fontes do Amaral Pereira; Dr. Rodolfo Wendhausen Krause; Dra. Sara Joana Gadotti dos Anjos; e Dra. Yolanda Flores e Silva.

No mesmo ano, o PPGTH, em cooperação com a graduação em Turismo e Hotelaria e a graduação em Gastronomia da UNIVALI, criou o Fórum Científico de Gastronomia, Turismo e Hotelaria (FCGTurH), com o objetivo de desenvolver um local propício para a troca de conhecimento entre pesquisadores, docentes, discentes e profissionais das áreas do turismo, hotelaria e gastronomia. O evento, desde o seu início até os dias atuais, se destaca pela participação de renomados palestrantes em suas edições, como: Doutor Mario Carlos Beni; Me. Jun Alex Yamamoto (Coordenador Geral de Regionalização do Ministério do Turismo); Prof. PhD. Jafar Jafari (Winsconsin University - EUA); Prof. Dr. João Albino Matos da Silva 
(Universidade do Algarve - Portugal); Prof. PhD. Miguel Moital (Bournermouth University - Inglaterra); Prof. Dra. Doris Van de Meene Ruschmann; Prof. ${ }^{a}$ PhD. Maria Velasco González (Universidad Complutense de Madrid - Espanha); Prof. Dr. Wilker Ricardo de Mendonça Nóbrega; Prof. ${ }^{a}$ Dra. Margarita Nilda Barretto Angeli; Prof. Dr. Lluís Mundet i Cerdan (Universitat de Girona - Espanha); Prof. Armin Brysch (Kempten University oh Applied Sciences - Alemanha).

A primeira defesa de doutorado ocorreu no dia 31 de agosto de 2015, com a tese intitulada "Gestão do destino turístico modelo de avaliação da experiência do turista com base nas online travel review", de autoria de Pablo Flôres Limberger, sob orientação da professora Dra. Sara Joana Gadotti dos Anjos. Compuseram a mesa de avaliação os seguintes membros: Prof. Dr. Júlio Da Costa Mendes (UALg/Portugal); Prof. Dr. Silvio Luiz Gonçalves Vianna (Ucs/ RS); Prof. Dr. Clóvis Reis (Furb/SC); Prof. a Dra. Fabrícia Durieux Zucco (UNIVALI); e Prof. Dr. Francisco Antonio dos Anjos (UNIVALI).

O PPGTH atualmente está reforçando as suas parcerias em busca de um fortalecimento da instituição no cenário internacional. Até o momento o Programa de Pós-Graduação em Turismo e Hotelaria tem um acordo de Dupla Diplomação de Mestrado e Doutorado em Gestão de Destinos Turísticos com a Universidade do Algarve - UALg- Portugal, um acordo de colaboração de pesquisa e orientação de doutorado em Turismo com a Universidade de Alicante - Espanha; e um acordo de Co-Tutela de Doutorado em Turismo com a Universidade de Girona - Espanha.

Além destes acordos existem parcerias formadas para a realização do estágio sanduíche de doutorado com as seguintes universidades: Universidade do Algarve - Portugal; Universidade de Lisboa - Portugal; Universidade de Alicante - Espanha; Universidade de Girona - Espanha; Universidade de Bremmen Alemanha; Modul Universit - Viena - Áustria; Universidade de Surrey -Inglaterra. No momento novos acordos estão em andamentos com a Universidade Central da Flórida (EUA) e a Universidade Complutense de Madri (Espanha). Estes acordos de doutorado sanduíche foram fundamentais para a ida de 12 alunos para estas instituições desde o ano de 2013. Destaca-se o ano de 2017, com 6 alunos em diferentes universidades realizando os seus doutorados. 
O PPGTH, por meio dos seus docentes, mantém parcerias com outros pesquisadores de outros países em colaborações para as pesquisas, além de publicações em periódicos internacionais e participações em eventos de porte internacional em países como Inglaterra, Espanha, França, Estados Unidos, Portugal, Grécia e outros.

No decorrer destes 20 anos do PPGTH, o Programa teve um total de 60 docentes lecionando e pesquisando sob a gestão dos seguintes coordenadores: Prof. ${ }^{a}$ Dra. Doris van de Meene Ruschmann; Prof. Dr. Paulo dos Santos Pires; Prof. Dr. Francisco Antonio dos Anjos; e Prof. ${ }^{a}$ Dra. Josildete Pereira de Oliveira. Durante os 20 anos do curso foram formados 365 mestres e 06 doutores. Estes fomentam um ensino de qualidade em diversas universidades do Brasil e ajudam a construir um conhecimento científico do turismo e da hotelaria disseminado internacionalmente nos principais periódicos e eventos da área. 